\title{
Towards closing the gap between hygroscopic growth and activation for secondary organic aerosol - Part 2: Theoretical approaches
}

\author{
M. D. Petters ${ }^{1}$, H. Wex ${ }^{2}$, C. M. Carrico ${ }^{1}$, E. Hallbauer ${ }^{2}$, A. Massling ${ }^{2,}{ }^{*}$, G. R. McMeeking ${ }^{1, * *}$, L. Poulain ${ }^{2}$, Z. Wu ${ }^{2}$, \\ S. M. Kreidenweis ${ }^{1}$, and F. Stratmann ${ }^{2}$ \\ ${ }^{1}$ Department of Atmospheric Science, Colorado State University, Fort Collins, CO, USA \\ ${ }^{2}$ Institute for Tropospheric Research, Leipzig, Germany \\ *now at: National Environmental Research Institute, Aarhus University, Roskilde, Denmark \\ ** now at: Centre for Atmospheric Science, University of Manchester, Manchester, UK
}

Received: 22 September 2008 - Published in Atmos. Chem. Phys. Discuss.: 12 December 2008

Revised: 18 March 2009 - Accepted: 14 April 2009 - Published: 18 June 2009

\begin{abstract}
We examine the hygroscopic properties of secondary organic aerosol particles generated through the reaction of $\alpha$-pinene and ozone using a continuous flow reaction chamber. The water activity versus composition relationship is calculated from measurements of growth factors at relative humidities up to $99.6 \%$ and from measurements of cloud condensation nuclei activity. The observed relationships are complex, suggesting highly non-ideal behavior for aerosol water contents at relative humidities less than $98 \%$. We present two models that may explain the observed water activity-composition relationship equally well. The first model assumes that the aerosol is a pseudo binary mixture of infinitely water soluble compounds and sparingly soluble compounds that gradually enter the solution as dilution increases. The second model is used to compute the Gibbs free energy of the aerosol-water mixture and shows that the aerosol behaves similarly to what can be expected for single compounds that contain a certain fraction of oxygenated and non-polar functional groups.
\end{abstract}

\section{Introduction}

Nucleation scavenging into water drops, followed by wet deposition, is the most important pathway for removal of fine particles from the atmosphere (Pöschl, 2005), and descriptions of nucleation scavenging require accurate knowledge

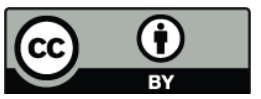

Correspondence to: M. D. Petters (petters@atmos.colostate.edu) of the hygroscopic properties of the aerosol. A number of recent studies have characterized the hygroscopic properties, including their ability to serve as cloud condensation nuclei $(\mathrm{CCN})$, of secondary organic aerosols (SOA) formed in the laboratory from known biogenic and anthropogenic precursors using a variety of oxidants and reaction conditions. To date several studies have also addressed hygroscopic water uptake by these particles under subsaturated conditions $(\mathrm{RH}<90 \%)$ (Virkkula et al., 1999; Saathoff et al., 2003; Varutbangkul et al., 2006; Prenni et al., 2007; Duplissy et al., 2008) as well as their ability to serve as CCN under supersaturated conditions (RH>100\%) (Hegg et al., 2001; Huff Hartz et al., 2005; VanReken et al., 2005; Asa-Awuku et al., 2007; King et al., 2007; Prenni et al., 2007; Duplissy et al., 2008; Engelhart et al., 2008). Combined, these studies suggest that pure SOA particles generated from different oxidants and precursors in the laboratory can serve as cloud droplet nuclei in naturally occurring clouds (i.e., at supersaturations exceeding $0.1 \%$ ) if their size exceeds $\sim 60-120 \mathrm{~nm}$. There is a remarkable consistency in hygroscopic behavior among the various systems studied thus far, for either the subsaturated or the supersaturated regime, despite the broad range of choices of precursor hydrocarbon and oxidation conditions. In contrast, there appears to be an inconsistency between hygroscopicity determined from the sub- and supersaturated experiments for many (Prenni et al., 2007) but not all (Duplissy et al., 2008) SOA types studied so far, with particles being more $\mathrm{CCN}$ active than anticipated by the extrapolation from hygroscopic growth measurements. Prenni et al. (2007) proposed several possible explanations for the observed "hygroscopicity gap", but could not distinguish among various

Published by Copernicus Publications on behalf of the European Geosciences Union. 
hypothesized explanations, in part because water uptake data for $92 \%<\mathrm{RH}<100.3 \%$ could not be obtained with their instrumentation.

In a companion manuscript (Wex et al., 2009) we present hygroscopic growth factors measured at up to $99.6 \%$ relative humidity with the Leipzig Aerosol Cloud Interaction Simulator (LACIS) (Stratmann et al., 2004) and CCN activity measured with a Droplet Measurement Technologies (DMT) continuous flow CCN instrument (Roberts and Nenes, 2005; Lance et al., 2006; Rose et al., 2008). Measurements were made for SOA generated from the dark ozonolysis of $\alpha$ pinene in the presence and absence of an $\mathrm{OH}$ scavenger and in the presence and absence of water vapor. In Wex et al. (2009) we demonstrated that surface tension reduction at the point of droplet activation cannot account fully for the observed differences between subsaturated hygroscopic growth and CCN activity. Here, we further analyze the same data using two models. The first model is based on the single hygroscopicity parameter framework, including multiple components with varying solubilities (Petters and Kreidenweis, 2008), while the second model is based on the classic thermodynamic description of non-ideal solutions (Prausnitz et al., 1999).

\section{Experimental}

Details about the experimental methods and data reduction methods are discussed in our companion paper (Wex et al., 2009). Therefore, we only give a synopsis here. Secondary organic aerosol particles were generated inside a continuous flow reactor having a residence time of $\sim 2 \mathrm{~min}$, with separately controlled ozone and gaseous organic precursor input flows. The organic precursor can be mixed with butanol, an $\mathrm{OH}$ scavenger, prior to injection into the reaction vessel, and in some experiments the ozone flow was humidified before it entered the reaction vessel. No seed aerosol was used. SOA particles thus formed via homogeneous nucleation, reaching a steady-state size distribution and number concentration after $\sim 30 \mathrm{~min}$. The precursor concentrations and reaction conditions are summarized in Table 1.

The steady-state aerosol in the reactor outlet stream was size-selected using a differential mobility analyzer; the stream was split and sent to our hygroscopic growth measurement instruments. Subsaturated hygroscopic growth factors were measured using LACIS (Stratmann et al., 2004), which consists of a laminar flow tube and optical particle spectrometer that measures the size of the particles that exit the tube. We also show a limited set of growth factors obtained from a hygroscopic tandem differential mobility analyzer (HTDMA) system. The system and data reduction methods used are identical to those described in Prenni et al. (2007). For data from both LACIS and the HTDMA, the ratio of grown diameter to dry diameter defines the hygroscopic growth factor, $D / D_{d}$. If the SOA particles are liq-
Table 1. SOA samples under different Reaction conditions.

\begin{tabular}{lllll}
\hline reaction conditions & type & precursor & OH scavenger & dew point \\
\hline $\mathrm{O}_{3}+$ butanol & I & $\alpha$-pinene & yes $(10: 1)$ & $-40^{\circ} \mathrm{C}$ \\
$\mathrm{O}_{3}$ & II & $\alpha$-pinene & no & $-40^{\circ} \mathrm{C}$ \\
$\mathrm{O}_{3}+\mathrm{H}_{2} \mathrm{O}+$ butanol & III & $\alpha$-pinene & yes $(10: 1)$ & $18^{\circ} \mathrm{C}$ \\
\hline
\end{tabular}

uid and spherical, as assumed here, shape corrections to the geometric sizes inferred from mobility and optical sizes are unnecessary, but these assumptions may not apply to SOA formed from dark ozonolysis of $\alpha$-pinene (Bahreini et al., 2005). Nonsphericity introduces additional uncertainty in the measured growth factors that is not accounted for here.

We measured supersaturations required for activation to cloud particles by stepping through a range of dry, chargeneutralized, mobility-selected diameters at fixed supersaturation in the CCN instrument. Scans were conducted over the range of supersaturations, $s=0.1$ to $1 \%$. The resulting $\mathrm{CCN}$ response curves were inverted using a multiple charge correction algorithm (Petters et al., 2007) to find the activation diameter at the specified supersaturation. The instrument supersaturation was calibrated using ammonium sulfate and assuming that the relationship between critical supersaturation and dry diameter for ammonium sulfate is described by $\kappa=0.6$ (Petters and Kreidenweis, 2007), which is based on water activity versus composition relationship from the Aerosol Inorganic Model (Clegg et al., 1998). Assuming $\kappa=0.6$ for ammonium sulfate leads to a relative error on the order of a few percent in calculated critical supersaturations for $D_{d}<40 \mathrm{~nm}$ when compared to the Aerosol Inorganic Model.

\section{Models for data analysis}

\subsection{Single parameter hygroscopicity}

The Köhler equation relates the saturation ratio, $S=\mathrm{RH} / 100$, to water activity and the Kelvin term

$S=a_{w} \exp \left(\frac{4 \sigma_{s / a} M_{w}}{R T \rho_{w} D}\right)$

where $a_{w}$ is the activity of water in solution, $\rho_{w}$ is the density of water, $M_{w}$ is the molecular weight of water, $\sigma_{s / a}$ is the surface tension of the solution/air interface, $R$ is the universal gas constant, $T$ is temperature, and $D$ is the diameter of the droplet. We use the single parameter representation of Petters and Kreidenweis (2007) to analyze the effect of the solute on the solution. Several other, essentially equivalent, expressions have been suggested in the literature (Svenningsson et al., 1994; Rissler et al., 2006; Wex et al., 2007) and 
could also be used for these analyses. Petters and Kreidenweis defined the hygroscopicity parameter $\kappa$ by

$a_{w}^{-1}=1+\kappa \frac{V_{s}}{V_{w}}$,

where $V_{s}$ is the volume of the dry particulate matter and $V_{w}$ is the volume of the water. The hygroscopicity parameter can be obtained directly from growth factor versus saturation ratio measurements via

$\kappa=\left(\left[D / D_{d}\right]^{3}-1\right)\left(\exp \left(\frac{4 \sigma_{s / a} M_{w}}{R T \rho_{w} D}\right) \times S^{-1}-1\right)$,

where $D_{d}$ is the dry particle diameter. In the fitting of $\kappa$ to growth factor data, the solution surface tension was here assumed to be equal to the surface tension of water, $0.072 \mathrm{~J} \mathrm{~m}^{-2}$; this assumption had minimal impact on the derived water activities from growth factor data for the dry sizes chosen in this study $(0.25-0.35 \mu \mathrm{m})$. Using Eq. (2), and assuming volume additivity, Petters and Kreidenweis (2007) show that the Köhler curve is given by

$S(D)=\frac{D^{3}-D_{d}^{3}}{D^{3}-D_{d}^{3}(1-\kappa)} \exp \left(\frac{4 \sigma_{s / a} M_{w}}{R T \rho_{w} D}\right)$.

The critical supersaturation $\left(s_{c}\right.$, where $s_{c}=S_{c}-1$ and is usually expressed as a percentage) for a selected dry diameter of a particle having hygroscopicity $\kappa$ is computed from the maximum of Eq. (4).

For most organic compounds found in the atmosphere, including many mono-, di-, and poly-carboxylic acids, monoand di-sugars, fulvic and humic acids, $\kappa$ derived from growth factor measurements and $\kappa$ derived from $\mathrm{CCN}$ measurements agree within measurement uncertainties, suggesting that variations in $\kappa$ with relative humidity are generally small (Petters and Kreidenweis, 2007; Carrico et al., 2008; Chan et al., 2008). In contrast to this result, the SOA data analyzed here and elsewhere (Prenni et al., 2007; Wex et al., 2009) suggest that $\kappa$ varies by a factor of 4-6 in the subsaturated regime when extending the measurements to RH near $100 \%$. One possible explanation for this behavior is the gradual dissolution, with increasing RH and thus $V_{w}$, of compounds that are only sparingly soluble in water. For species that contain $i$ multiple components, each having unique solubilities and hygroscopicities that conform to Eq. (2), the following mixing rule can be used to calculate the hygroscopicity parameter (Petters and Kreidenweis, 2008):

$$
\begin{aligned}
& \kappa=\sum_{i} \varepsilon_{i} \kappa_{i} H\left(a_{i}\right) \\
& a_{i}=\left(\left[D / D_{d}\right]^{3}-1\right) C_{i} / \varepsilon_{i} \\
& H\left(a_{i}\right)=\left\{\begin{array}{cc}
a_{i} & a_{i}<1 \\
1 & a_{i} \geq 1
\end{array} .\right.
\end{aligned}
$$

In Eq. (5) $\varepsilon_{i}$ denotes the volume fraction in the dry particle, $\kappa_{i}$ the hygroscopicity, $a_{i}$ the dissolved solute fraction, and $C_{i}$ the solubility (expressed as volume of solute

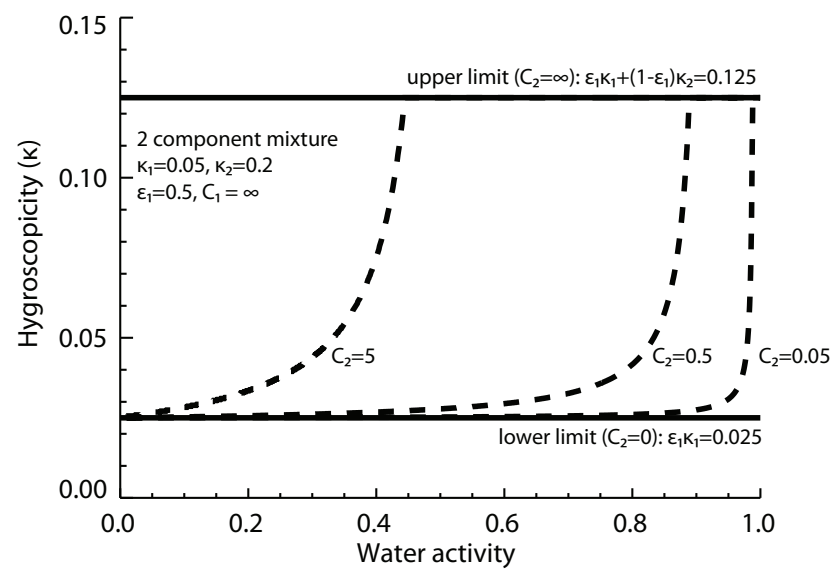

Fig. 1. Variation of the hygroscopicity parameter with water activity for an illustrative two component mixture with equal volume fractions of component 1 and 2 in the mixture. Assumed hygroscopicities and solubilities are $\kappa_{1}=0.05, \kappa_{2}=0.2, C_{1}=\infty, C_{2}=(0$, $0.05,0.5,5, \infty)$.

per unit volume of water present in a saturated solution) of the i-th component. Figure 1 shows an illustrative example of this model assuming a two-component mixture, with one infinitely soluble compound having hygroscopicity $\kappa_{1}=0.05$ and one compound having solubility $C_{2}=(0,0.05$, $0.5,5, \infty)$ and $\kappa_{2}=0.2$. If compound 2 is insoluble, i.e. $C_{2}=0$, only compound 1 will contribute to the hygroscopicity through the mixing rule and $\kappa=\varepsilon_{1} \kappa_{1}=0.025$. Similarly, if compound 2 is infinitely soluble the mixing rule states that $\kappa=\varepsilon_{1} \kappa_{1}+\left(1-\varepsilon_{1}\right) \kappa_{2}=0.125$. In both cases $\kappa_{i}$ are assumed invariant over the entire range of water activity. For choices of intermediate values of solubility, the overall hygroscopicity transitions between the lower and upper hygroscopicity limits. The value of the solubility determines the water activity where the transition occurs. Lower solubility requires higher water activity to lead to dissolution and the corresponding transition to the upper hygroscopicity limit. We note that components 1 and 2 as defined in this model do not necessarily need to consist of a single compound. Each can be thought of as a mixture of many compounds that have similar solubilities. The hygroscopicity of compound 1 is then the volume weighted hygroscopicity of all individual compounds that are infinitely soluble. Similarly, the hygroscopicity of compound 2 is the volume weighted hygroscopicity of all individual compounds that are sparingly soluble. We therefore refer to this model as the pseudo two-component hygroscopicity model.

Figure 2 shows the variation of the fitted hygroscopicity parameter with water activity derived from LACIS and HTDMA measurements. For $a_{w}<\sim 0.98$ the hygroscopicity parameter is $\kappa \sim 0.01$ for Type I and II SOA and slightly larger for Type III, and has a value of $\kappa \sim 0.018$. At larger water activities hygroscopicity increases, with values approaching 

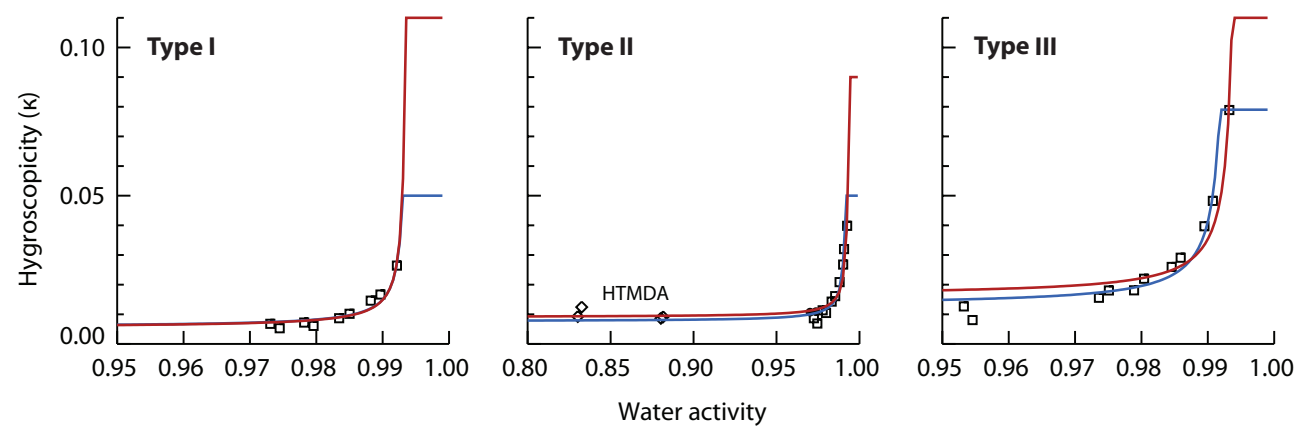

Fig. 2. Observed variation of the hygroscopicity parameter with water activity for the three aerosol types. Colored lines indicate a fitted two-component hygroscopicity model. The red and blue lines assume a different prescribed upper limit hygroscopicity.
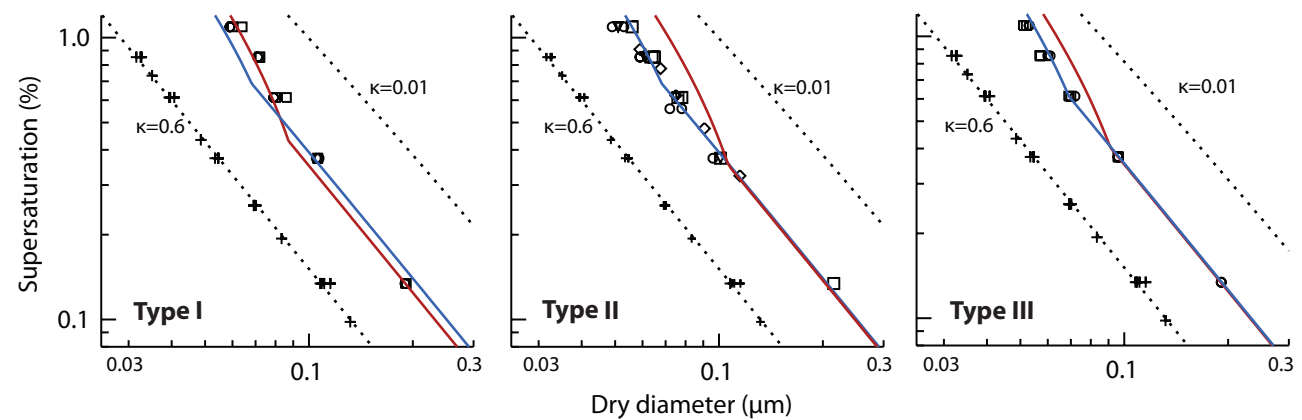

Fig. 3. Measured CCN activity for the three SOA types (opens symbols); different symbols indicate repeats of the experiment on different days. Plus (+) symbols show the calibration data for ammonium sulfate aerosol. Dotted lines indicate the single parameter representation of the relationship between critical supersaturation and dry diameter as defined in Petters and Kreidenweis (2007). Red and blue lines show the modeled CCN activity for the two-component model with one sparingly soluble compound. Colors are consistent with the plots in Fig. 2. Parameters for the fits and assumed surface tensions are summarized in Table 2.

$\kappa=0.1$ for one of the samples. SOA particles that were generated without an $\mathrm{OH}$ scavenger are slightly more hygroscopic at all water activities. In the presence of water vapor during the reaction (Type III) the aerosol is more hygroscopic than both Types I and II.

We use Eq. (5) to fit the proposed two-component model to the LACIS-derived subsaturated hygroscopicity data. This model requires five input parameters: hygroscopicity for components 1 and 2, solubility for components 1 and 2, and the volume fraction of component 1 in the dry aerosol. In this study, as well as in previous studies of hygroscopic growth of SOA particles (Virkkula et al., 1999; Varutbangkul et al., 2006; Prenni et al., 2007) water uptake was observed to be continuous with no clear deliquescence transition, suggesting that at least one compound must be water soluble even in concentrated solutions. We therefore assume that component 1 is infinitely soluble. If only component 1 is dissolved, the product $\varepsilon_{1} \kappa_{1}$ must evaluate to $\sim 0.01$. A choice of $\varepsilon_{1}$ constrains $\kappa_{1}$, and vice versa. Once the mixture is sufficiently dilute the second component becomes completely dissolved and overall hygroscopicity asymptotes to $\kappa=\varepsilon_{1} \kappa_{1}+\left(1-\varepsilon_{1}\right) \kappa_{2}$. However, our data set is not sufficient to determine $\varepsilon_{1}, \kappa_{1}$, and $\kappa_{2}$ independently since we do not have data over the entire range of water activity; in fact, an infinite number of solutions exists. Here we propose the following procedure to describe the observed relationship: we prescribe a constant surface tension, choose a value for $\kappa_{1}=\kappa_{2}$, set $C_{1}=\infty$ and then fit the data to find $\varepsilon_{1}$ and $C_{2}$. Because we limit, for now, our fitting to subsatured data only, the choice of surface tension is not critical here. Fits for two choices of $\kappa_{i}$, an upper and lower estimate that will be explained below, could be determined that give good agreement with the data in Fig. 2, as shown by the lines in the figure. Values for the prescribed and fitted parameters are summarized in Table 2.

The models can then be used to predict the relationship between critical supersaturation and dry diameter, observed values for which are shown in Fig. 3. These predicted critical supersaturations are sensitive to the assumed surface tension, much more than is the hygroscopic growth factor (Wex et al., 2009). We chose the upper limit $\kappa=\kappa_{1}=\kappa_{2}$, i.e. $\kappa=0.11,0.09$, and 0.11 for the three aerosol types, for the fitting of the water activity data to bring the $\mathrm{CCN}$ data into agreement with the model for the assumption of a constant surface tension equal to that of pure water. In Wex et al. (2009) we show that the surface tension may be as low as $\sigma_{s / a} \sim 0.060-0.065 \mathrm{~J} \mathrm{~m}^{-2}$. This value for surface tension leads to the choice of our lower 
Table 2. Prescribed and fitted parameters for models used in this study. Values in columns 3-5 are prescribed, columns 6, 7 are fitted based on LACIS data and column 8 is fitted based on CCN data. All parameters are unitless except for $\sigma_{s / a}$, which is given in $10^{-3} \mathrm{~J} \mathrm{~m}{ }^{-2}$. The column "line color" indicates the parameters corresponding to the red and blue lines in Figs. 2 and 3.

\begin{tabular}{|c|c|c|c|c|c|c|c|c|c|c|c|c|c|}
\hline \multirow{2}{*}{ Reaction conditions } & \multirow{2}{*}{ Line color } & \multicolumn{6}{|c|}{ Two-component model } & \multicolumn{6}{|c|}{ Non-ideal model } \\
\hline & & $\kappa_{1}$ & $\kappa_{2}$ & $C_{1}$ & $C_{2}$ & $\varepsilon_{1}$ & $\sigma_{s / a}$ & $\alpha_{1}$ & $\beta_{1}$ & $\alpha_{2}$ & $\beta_{2}$ & $f$ & $\sigma_{s / a}$ \\
\hline \multirow{2}{*}{$\mathrm{O}_{3}+$ butanol } & red & 0.11 & 0.11 & $\infty$ & 0.057 & 0.051 & 72 & \multirow{2}{*}{1.37} & \multirow{2}{*}{1.18} & \multirow{2}{*}{0} & \multirow{2}{*}{0} & \multirow{2}{*}{0.1} & \multirow{2}{*}{65} \\
\hline & blue & 0.05 & 0.05 & $\infty$ & 0.125 & 0.114 & 60 & & & & & & \\
\hline \multirow{2}{*}{$\mathrm{O}_{3}$} & red & 0.09 & 0.09 & $\infty$ & 0.066 & 0.153 & 72 & \multirow{2}{*}{0.665} & \multirow[b]{2}{*}{1.18} & \multirow[b]{2}{*}{0.68} & \multirow{2}{*}{1.19} & \multirow{2}{*}{0.1} & \multirow[b]{2}{*}{60} \\
\hline & blue & 0.05 & 0.05 & $\infty$ & 0.143 & 0.100 & 60 & & & & & & \\
\hline \multirow{2}{*}{$\mathrm{O}_{3}+\mathrm{H}_{2} \mathrm{O}$} & red & 0.11 & 0.11 & $\infty$ & 0.050 & 0.148 & 72 & \multirow{2}{*}{1.41} & \multirow{2}{*}{1.24} & \multirow[b]{2}{*}{0} & \multirow[b]{2}{*}{0} & \multirow{2}{*}{0.1} & \multirow{2}{*}{65} \\
\hline & blue & 0.079 & 0.079 & $\infty$ & 0.088 & 0.163 & 65 & & & & & & \\
\hline
\end{tabular}

limit $\kappa, 0.05-0.069$, required to again brings the water activity model and the $\mathrm{CCN}$ observations into agreement. As we demonstrated earlier, it is the solubility of the second, lower-solubility component that determines the water activity where the change in the overall hygroscopicity becomes pronounced. The observed increase at $a_{w} \sim 0.98$ therefore constrains the choice of solubility, within an order of magnitude, to $C_{2} \sim 0.1$, as seen in Table 2 . The two component model, in conjunction with water activity data up to $99.6 \%$ $\mathrm{RH}$, is not well enough constrained to allow us to pinpoint accurately to what extent cloud drop activation was controlled by a reduced surface tension and lower hygroscopicity or a larger hygroscopicity without a surface tension reduction.

\subsection{Non-ideal model}

The Gibbs free energy of a system expresses the degree of non-ideality of a mixture due to changes in composition. By tracing the changes in Gibbs free energy with overall component mole fraction, information about the number of phases may also be ascertained (e.g., Amundson et al., 2007). Normalized Gibbs free energy $(g)$ is unitless and is the actual Gibbs free energy divided by the thermal energy, $R T$. Normalized Gibbs free energies of mixtures are readily calculated from activity coefficient versus mole fraction relationships (Prausnitz et al., 1999)

$$
\begin{aligned}
& g^{\text {ideal }}=x_{w} \ln x_{w}+\left(1-x_{w}\right) \ln \left(1-x_{w}\right) \\
& g^{\text {excess }}=x_{w} \ln \gamma_{w}+\left(1-x_{w}\right) \ln \gamma_{s} \\
& g^{\text {mix }}=g^{\text {ideal }}+g^{\text {excess }}
\end{aligned}
$$

In Eq. (6) $x_{w}$ denotes the mole fraction of water in the mixture and $\gamma_{w}$ and $\gamma_{s}$ are the activity coefficients of water and dry aerosol components. To convert our observed variables $\left(V_{w}, V_{s}\right.$, and $\left.D / D_{d}\right)$ into overall mole fractions we write

$$
\begin{aligned}
\frac{1}{x_{w}} & =1+\sum \frac{n_{s, i}}{n_{w}}=1+\sum \varepsilon_{i} \frac{M_{w} \rho_{s, i}}{M_{s, i} \rho_{w}} \frac{V_{s}}{V_{w}}=1+f \frac{V_{s}}{V_{w}} \\
& =\frac{\left(D / D_{d}\right)^{3}+f-1}{\left(D / D_{d}\right)^{3}-1} \\
f & =\sum \varepsilon_{i} \frac{M_{w} \rho_{s, i}}{M_{s, i} \rho_{w}},
\end{aligned}
$$

where $M_{s, i}$ are the molecular weights, $\rho_{s, i}$ are the densities, and $n_{s, i}$ are the number of moles dry aerosol components. As defined earlier $\varepsilon_{i}$ denotes the volume fraction of the i-th component in the dry mixture. In writing water mole fractions in terms of the growth factor and the parameter $f$ we have assumed that volumes are additive. The physical interpretation of $f$ is the average ratio of the molecular volumes of the water and dry aerosol components. For molecules of similar size compared to water $f \approx 1$ while for larger molecules $f<1$, approaching zero for macromolecules. For nonideal mixtures the activity coefficient of water is defined as

$\gamma_{w}=\frac{a_{w}}{x_{w}}=a_{w} \frac{\left(D / D_{d}\right)^{3}+f-1}{\left(D / D_{d}\right)^{3}-1}$.

Thus if we assume a value for $f, \gamma_{w}$ can be obtained from the growth factor versus water activity measurements. To obtain $\gamma_{s}$ we use the Gibbs-Duhem equations which states that

$x_{w} d \ln \gamma_{w}+\left(1-x_{w}\right) d \ln \gamma_{s}=0$,

must hold. In Eq. (9) $1-x_{w}=x_{s}$ and is the mixture mole fraction of the dry aerosol components. Since SOA can be comprised of hundreds of components, each having individual activity coefficients, $\gamma_{s}$ is here treated as the overall average activity coefficient, that can, in principle, be constructed from the activity coefficients and mole fractions of the individual components. The average activity coefficient can be obtained from numerical integration of Eq. (9) using the inferred water activity versus composition data as a starting point. However, the data do not span the entire composition range. To extrapolate to more concentrated and to more dilute concentrations, water activity-composition data can also be fit to the empirical activity coefficient model suggested by Margules (Prausnitz et al., 1999):

$$
\ln \gamma_{w}=\ln \left(a_{w} / x_{w}\right)=\sum_{j} \alpha_{j}\left(1-x_{w}\right)^{\beta_{j}}
$$

where $\alpha_{j}$ and $\beta_{j}$ are empirical constants determined from the fitting. In accordance with the Gibbs-Duhem equation, the activity coefficient of the solute can then be calculated from

$$
\ln \gamma_{s}=\sum_{j} \alpha_{j}\left(1-x_{w}\right)^{\beta_{j}}-\sum_{j} \frac{\alpha_{j}}{\beta_{j}-1}\left(\beta_{j}\left[1-x_{w}\right]^{\beta_{j}-1}-1\right)
$$


Table 3. Properties of several products identified in secondary organic aerosol.

\begin{tabular}{llllll}
\hline Compound & Density $\left(\mathrm{g} \mathrm{cm}^{-3}\right)$ & $\mathrm{M}_{S}\left(\mathrm{~g} \mathrm{~mol}^{-1}\right)$ & $\mathrm{f}$ & $\mathrm{CCN} \kappa^{\mathrm{a}}$ & Solubility $^{\mathrm{b}}$ \\
\hline adipic acid & 1.36 & 146 & 0.16 & 0.09 & $0.013-0.014$ \\
pinic acid & 0.80 & 186 & 0.07 & 0.25 & $>0.1$ \\
pinonic acid & 0.78 & 184 & 0.08 & 0.11 & $0.008-0.009$ \\
\hline
\end{tabular}

${ }^{\text {a }}$ Hygroscopicity values are reported in Petters and Kreidenweis (2007) based on the data of Raymond and Pandis (2002).

b Solubilities are expressed as volume of solute per unit volume of water present in a saturated solution. Values are from Raymond and Pandis (2002).
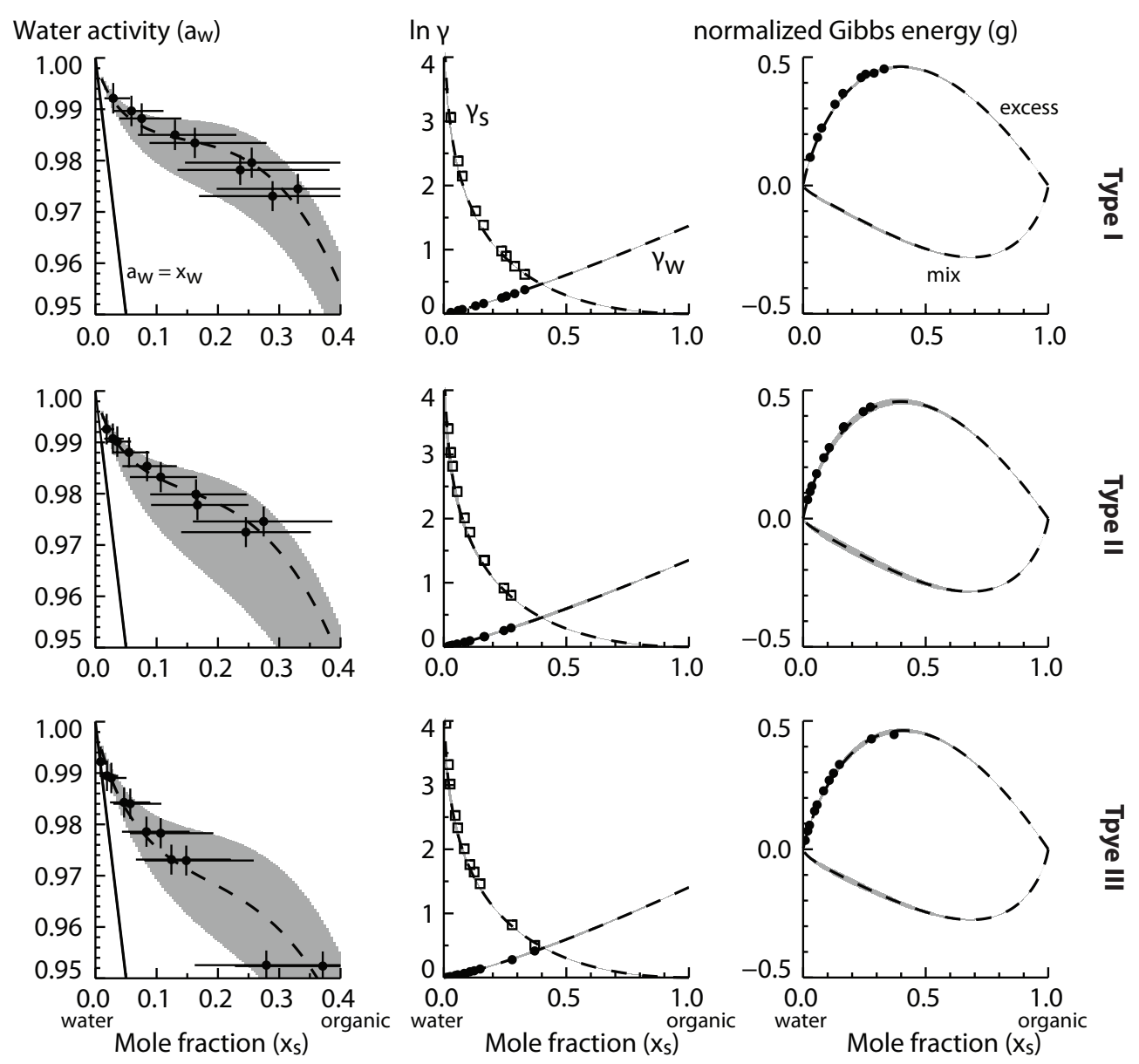

Fig. 4. Real solution theory applied to LACIS measurements for the three SOA types. Dashed lines are calculated from the fitted coefficients given in Table 2 and Eqs. (9)-(11). Horizontal bars in the left plots show uncertainties in the derived mole fraction based on a range of values for the normalized average molecular volume $(0.2<f<0.05)$. Vertical lines correspond to the estimated uncertainty in relative humidity in LACIS. Gray shaded area in all plots denotes the estimated uncertainty in the fit based on excursions in the fitted parameters. See text for details.

It is thus possible to compute $g^{\text {mix }}$ and $g^{\text {excess }}$ from Eqs. (6-11). Figure 4 shows water activity versus composition relationships for the three SOA types (left panels), derived activity coefficients for water and aerosol components (middle panels) and $g^{\text {mix }}$ and $g^{\text {excess }}$ (right panels). The value of $f$, i.e. the average ratio of molecular volume of dry aerosol components to water, is unknown and we assumed that a reasonable choice is $f=0.1$ and that $0.05<f<0.2$ provide realistic bounds, based on the properties of dominant compounds that have been identified in aerosols generated from $\alpha$-pinene oxidation, as shown in Table 3. However, values of $f$ may be smaller than 0.05 if oligomerization 
(Kalberer et al., 2004; Baltensperger et al., 2005) occurred in the condensed phase. We used a non-linear least squares curve fitting method to fit the derived $\gamma_{w}$ values (middle panels) to Eq. (10). The fitted parameters are summarized in Table 2. We calculated the uncertainty in water mole fraction based on the $0.05<f<0.2$ interval and this uncertainty is indicated by the horizontal error bars in the left panels. We note that uncertainties in the mole fraction shown in the left panels cannot be plotted in the same way in the middle panels because the error in derived water activity propagates into the derived activity coefficients, i.e. a larger $x_{w}$ (calculated from a smaller assumed $f$ ) implies a smaller $\gamma_{w}$. We therefore represent the uncertainty in $f$ by modifying the slope of the $x_{w}$ versus $\gamma_{w}$ relationship by manually adjusting $\alpha_{1}$ to find bounds that approximately envelope the error bars on the $a_{w}$ versus $x_{w}$ data points. This envelope is shown by the gray shaded region in all panels. Because $x_{w}$ is plotted versus $\ln \gamma_{w}$ in the middle panel, the gray shaded region appears smaller in the middle panels than in the left panels. We plot the $x_{w}$ versus $\gamma_{s}$ relationships from the numerical integration (points) and the fitted parameters using Eq. (11) (lines) to illustrate both the expected functional relationship of $x_{w}$ versus $\gamma_{s}$ and the range where data are available for fitting. Finally, using Eq. (11) we plot the $g^{\text {excess }}$ and $g^{\text {mix }}$ in the right panels. Uncertainties propagated from the assumed range in $f$ are indicated by the gray shaded areas.

Results from the preceding analysis suggest that the SOA solutions are highly non-ideal (values of $g^{\text {excess }}>0$ ) and that they lower the vapor pressure of water over the solution less than predicted by Raoult's law $\left(a_{w}=x_{w}\right)$, as seen by the derived $\gamma_{w}>1$. Deviations from ideal behavior occur at $a_{w}<\sim 0.995$ and the magnitude of the deviation depends on the reaction conditions. This can be seen best by comparing the ideal solution theory lines with the actual water activity versus mole fraction relationships for Type I,II, III aerosols plotted in the three panels on the left in Fig. 4. When the oxidation proceeds in the presence of water vapor (Type III), the solutions behave more ideally than in the case where oxidation proceeds with an $\mathrm{OH}$ scavenger and in the absence of water vapor (Type I), particularly for concentrated solutions. The non-ideality, expressed by the positive $g^{\text {excess }}$, is skewed towards dilute solutions for all types, leading to an asymmetric shape of the $g^{\text {mix }}$. Interestingly, the values and shape of the $g^{\text {mix }}$ versus composition relationship are similar to those predicted by the UHAERO model (Amundson et al., 2007 ) for the major $\alpha$-pinene oxidation products adipic acid, pinic acid, and pinonic acid (c.f. their Fig. 1). UHAERO uses functional group interaction parameters that are obtained by fitting the UNIFAC model (see also Ming and Russell, 2002; Topping et al., 2005) to measured data to determine the water activity versus solute mole fraction relationships, the normalized Gibbs free energies, and the phase equilibria. Amundson et al. point out that: 1$)$ it is the number and quality $\left(\mathrm{CH}_{2}\right.$, $\mathrm{OH}, \mathrm{CO}, \mathrm{CHO}$, or $\mathrm{COOH}$ ) of functional groups that determines $g^{\text {mix }}$, and hence the extent to which the system devi- ates from ideal behavior, even for binary solutions; 2 ) as the non-ideality increases, the probability increases that multiple stable phases are involved for at least some mole fractions of water in the mixture. From the shape of our $g^{\text {mix }}$ curves we see no clear indication that our aerosol underwent phase separation, but our data are too uncertain, and do not cover the entire composition space to show definitely whether phase separation occurred.

The non-ideal solution model can be extrapolated to dilute conditions to predict the $\mathrm{CCN}$ activity of the particles. In the extrapolation, the derived $x_{s}$ versus $\gamma_{w}$ relationship is applied at dilute concentrations outside the range of the initial data set and a solution surface tension must be assumed. The corresponding Köhler equation is:

$$
\begin{aligned}
& S(D)=\gamma_{w} x_{w} \exp \left(\frac{4 \sigma_{s / a} M_{w}}{R T \rho_{w} D}\right) \\
& =\exp \left(\sum_{j} \alpha_{j}\left(1-x_{w}\right)^{\beta_{j}}\right)\left(\frac{D^{3}-D_{d}^{3}}{D^{3}-D_{d}^{3}[1-f]}\right) \exp \left(\frac{4 \sigma_{s / a} M_{w}}{R T \rho_{w} D}\right) .
\end{aligned}
$$

In Eq. (12) $\gamma_{w}$ corresponds to the form of Eq. (10) and $x_{w}$ to a rearranged form of Eq. (7) where $D_{d}^{3}=6 V_{s} / \pi$ was substituted for the solute volume, $D^{3}-D_{d}^{3}=6 V_{w} / \pi$ was substituted for the water volume and volume additivity was assumed. One advantage of Eq. (12) over the pseudo two-component hygroscopicity model is that it obviates the need to assume an upper limit for the hygroscopicity parameter. In the limit of an infinitely dilute solution the activity coefficient model ensures that $\gamma_{w}=1$. Thus it is possible to use the assumed model to extrapolate from the most dilute water activity observation to infinite dilution without further assumptions. Again we prescribe surface tension values that bring predictions using the extrapolated water activity model into agreement with the observed CCN data, as shown in Fig. 5. The surface tension that was assumed $\left(\sim 0.060-0.065 \mathrm{~J} \mathrm{~m}^{-2}\right)$ is reduced by 10 $15 \%$ from that of pure water.

\section{Discussion and conclusions}

Based on the hygroscopicity model, SOA solutions may be interpreted as a pseudo binary mixture of a set of infinitely water soluble compounds and a set of sparingly soluble compounds. As the haze droplet dilutes, gradual dissolution adds to the number of moles of solute that are in solution, resulting in an increase in the observed hygroscopicity. Data from only HTDMA and CCN measurements are not suitable to map out the transition between weakly hygroscopic (low $\kappa$ ) for subsaturated conditions and apparently more hygroscopic states for more dilute solutions relevant to cloud droplet activation. As we demonstrate here, data obtained from LACIS can fill this gap. Although the pseudo two-component hygroscopicity model is poorly constrained, i.e. multiple sets of hygroscopicity parameters, solubilities, and volume fractions can 


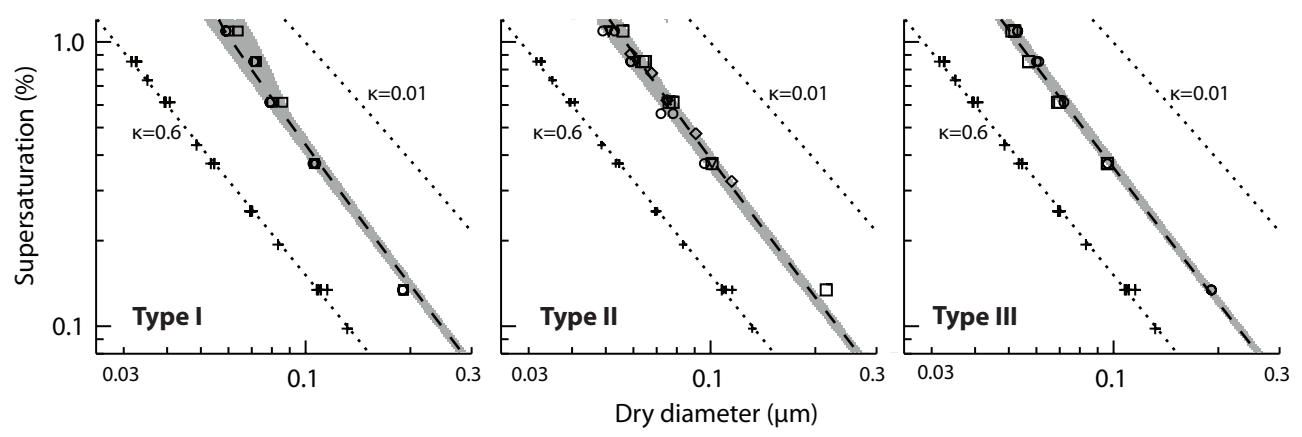

Fig. 5. Measured CCN activity for the three SOA types (open symbols); different symbols indicate repeats of the experiment on different days. Plus (+) symbols show the calibration data for ammonium sulfate aerosol. Dotted lines indicate the single parameter representation of the relationship between critical supersaturation and dry diameter as defined in Petters and Kreidenweis (2007). Dashed lines show predicted $\mathrm{CCN}$ activity based on the extrapolation of the fit to the non-ideal model (Fig. 4, parameters in Table 2). Gray shaded area corresponds to the uncertainty stemming from the assumed value for $f$, consistent with the gray shaded area in Fig. 2. Assumed surface tensions are summarized in Table 2.

be fit to the data, it can well represent the water activity versus composition data by reasonable choices of parameters. The solubility of the sparingly soluble compounds suggested by the fit to the data is larger than measured solubilities of pinonic acid and smaller than those for pinic acid (Table 3). Both of these compounds are likely to be found in the organic aerosol formed in this study.

Upon extrapolation to dilute solutions, the predicted CCN activity can be brought into agreement with the data assuming no or modest surface tension reduction, depending on the upper limit of the prescribed overall hygroscopicity parameter. The larger upper-limit hygroscopicity parameter requires higher surface tensions and does not reproduce the data well (i.e. red lines in Fig. 3). If the prescribed upper limit hygroscopicity parameter is reduced, and a reduced surface tension is assumed, the model and observations are in better agreement (i.e. blue curves in Fig. 3). The deduced surface tensions are reasonable; for example, Tuckerman and Cammenga (2004) report that pinonic acid reduces the surface tension of bulk aqueous solutions minimally for solute mole fractions of $10^{-2}-10^{-3}$, close to the solution concentrations expected at $\mathrm{CCN}$ activation. We note that we did not vary solution surface tension as a function of water content, as usually observed for aqueous solutions of carbonaceous compounds (e.g., Facchini et al., 1999; Ziese et al., 2008), because the data are too scant to permit us to constrain the concentration dependence in a meaningful way. Our reported surface tensions are therefore subject to uncertainty and are only indicative of the existence, and not the exact magnitude, of a surface tension effect.

We point out that the conceptual model that treats the system as one where gradual dissolution drives changes in hygroscopicity is not the only possible explanation. Our observed water uptake is similar to that of binary aqueous solutions of molecules known to be present in SOA (Amundson et al., 2007). The strong repulsive forces that $\mathrm{CH}_{2}$ groups exert on the solvating water are known as hydrophobic hydration and are expressed in the large positive $g^{\text {excess }}$. The main contribution to the excess free energy is thought to come from a structuring effect of the hydrophobic surface on the solvating water. Near the surface, hydrogen bonds between the water and the $\mathrm{CH}_{2}$ groups cannot form and water organizes in an ice-like structure (Frank and Evans, 1945). The molecular interpretation of the structuring effect is that the available entropy of mixing is reduced relative to that of an ideal mixture, thereby explaining the observed excess free energies. With the addition of more polar functional groups $(\mathrm{OH}, \mathrm{CO}, \mathrm{CHO}, \mathrm{COOH})$ the non-ideality of the solution diminishes. The hygroscopicity gap between concentrated and dilute mixtures can thus be understood to be caused by the relatively small number of oxygenated functional groups that form aerosol from the first generation terpene oxidation products. Duplissy et al. (2008) found that the discrepancy between sub- and super-saturated hygroscopicity disappears when reducing the amount of precursor used in the experiment. At low mass loadings, $\sim 10 \mathrm{ppb} \alpha$-pinene, the growth factor observed at $95 \% \mathrm{RH}$ was much larger than when using $183 \mathrm{ppb} \alpha$-pinene. In the low mass loading case, the hygroscopicity parameter derived at $95 \% \mathrm{RH}$ agreed with that inferred from $\mathrm{CCN}$ measurements, assuming the surface tension of pure water. Their aerosol mass spectra suggest that in the low mass loading case the aerosol was more oxygenated. Based on the Frank and Evans (1945) interpretation of the observed solution behavior, the degree of oxygenation is linked to the magnitude of $\mathrm{g}^{\text {excess }}$. As the reaction products become more polar, the repulsive forces that exert the structuring influence on the water decrease and thus $\mathrm{g}^{\text {excess }}$ is expected to decrease. This results in more ideal behavior at lower water activities, and thus the apparent discrepancy between sub- and super-saturated water uptake diminishes. In Fig. 4 it is apparent that the reaction conditions do indeed affect the deviation from the ideal solution behavior. In the 
presence of an $\mathrm{OH}$ scavenger (Type I) the solution behaves less ideally at lower water activity than in the absence of the $\mathrm{OH}$ scavenger (Type II) and in the presence of water and an $\mathrm{OH}$ scavenger (Type III). We presume that this difference is caused by differences in the number of functional groups associated with the carbon chain.

From a practical perspective the non-ideal solution model is well suited to fit the observed water activity versus composition data. The choice of activity coefficient model (here Eqs. 10 and 11) is not particularly important; others, e.g. the van Laar model or a Redlich-Kistner expansion (Prausnitz et al., 1999), could be chosen instead, depending on what fits the data best. The advantage of these models lies in their capability to extrapolate from the most dilute water activity observation to infinite dilution without further approximation, because the Gibbs-Duhem equation ensures that the equations are thermodynamically consistent at the dilute limit. A disadvantage is the fact that an average molecular volume (i.e. $f$ ) must be assumed first, and this parameter is not wellknown for complex multi-component aerosol types such as SOA. The assumption introduces significant uncertainty in the retrieved water mole fractions, particularly at low water contents. Despite this problem, the non-ideal solution model reproduces the $\mathrm{CCN}$ data. Uncertainty stemming from the assumption of $f$ has only a small effect on the prediction. Furthermore, the prescribed surface tensions are similar to those needed to fit data to the two-component hygroscopicity model, providing additional evidence that a small surface tension reduction in SOA solutions is likely present.

The CCN activities of SOA reported by various groups have been remarkably similar, despite variations in precursors, oxidation conditions, and mass loadings. In particular Prenni et al. (2007), King et al. (2007), Duplissy et al. (2008) and this work suggest that CCN activity of a-pinene SOA is well-modeled using the envelope $\kappa \sim 0.1 \pm 0.04, \sigma_{s / a}=0.072 \mathrm{~J} \mathrm{~m}^{-2}$. Although this view disregards the complexity of the underlying water activity relationship it suggests a concise parameterization of the activation behavior of monoterpene-derived SOA particles can be formulated. However, it should be noted that this approach is not appropriate when trying to connect hygroscopic growth and activation behavior of first generation organic aerosol derived from the ozonolysis of monoterpene precursors. The similar behavior of the SOA types studied thus far suggests that variations in molecular volumes and the degrees of oxygenation for the fresh SOA are similar enough to not significantly affect $\mathrm{CCN}$ activity, although this is not necessarily true for hygroscopic growth factors. To date most studies of $\mathrm{CCN}$ activity started with $\mathrm{C}_{6}$ (toluene, cyclohexene), $\mathrm{C}_{7}$ (cycloheptene), $\mathrm{C}_{10}$ (monoterpenes), and $\mathrm{C}_{15}$ (sesquiterpenes) precursors, giving rise to relatively small variations in the functionality and chain length of products that are likely found in the condensed phase. To determine if this is the reason for the similar observed $\mathrm{s}_{c}-D_{\text {dry }}$ relationships reported thus far, it will be necessary to contrast the $\mathrm{CCN}$ behavior observed for SOA created from $\mathrm{C}_{6}-\mathrm{C}_{15}$ precursors to that of SOA obtained from precursors having a much broader range of carbon numbers.

Acknowledgements. This work was funded in part by the National Science Foundation under grant ATM-0436196 and ATM-0521643. GRM was supported by a US Graduate Research Environmental Fellowship (GREF) funded by the US Department of Energy's Global Change Education Program. Furthermore the project was partly supported by EUROCHAMP (Integration of European Simulation Chambers for Investigating Atmospheric Processes). Logistical support was provided from the ACCENT (Atmospheric Composition Change, the European Network of Excellence) program Access to Infrastructures. We thank Paul J. Ziemann and Martin Gysel for useful discussions.

Edited by: K. Lehtinen

\section{References}

Amundson, N. R., Caboussat, A., He, J. W., Martynenko, A. V., Landry, C., Tong, C., and Seinfeld, J. H.: A new atmospheric aerosol phase equilibrium model (UHAERO): organic systems, Atmos. Chem. Phys., 7(17), 4675-4698, 2007.

Asa-Awuku, A., Nenes, A., Gao, S., Flagan, R. C., and Seinfeld, J. H.: Alkene ozonolysis SOA: inferences of composition and droplet growth kinetics from Köhler theory analysis, Atmos. Chem. Phys. Discuss., 7, 8983-9011, 2007, http://www.atmos-chem-phys-discuss.net/7/8983/2007/.

Bahreini, R., Keywood, M. D., Ng, N. L., Varutbangkul, V., Gao, S., Flagan, R. C., Seinfeld, J. H., Worsnop, D. R., and Jimenez, J. L.: Measurements of secondary organic aerosol from oxidation of cycloalkenes, terpenes, and m-xylene using an Aerodyne aerosol mass spectrometer, Environ. Sci. Technol., 39(15), 5674-5688, 2005.

Baltensperger, U., Kalberer, M., Dommen, J., Paulsen, D., Alfarra, M. R., Coe, H., Fisseha, R., Gascho, A., Gysel, M., Nyeki, S., Sax, M., Steinbacher, M., Prevot, A. S. H., Sjoren, S., Weingartner, E., and Zenobi, R.: Secondary organic aerosols from anthropogenic and biogenic precursors, Faraday Discuss., 130, 265-278, 2005.

Carrico, C. M., Petters, M. D., Kreidenweis, S. M., Collett, J. L., Engling, G., and Malm, W. C.: Aerosol hygroscopicity and cloud droplet activation of extracts of filters from biomass burning experiments, J. Geophys. Res., 113(D8), 08206, 2008.

Chan, M. N., Kreidenweis, S. M., and Chan, C. K.: Measurements of the Hygroscopic and Deliquescence Properties of Organic Compounds of Different Solubilities in Water and Their Relationship with Cloud Condensation Nuclei Activities, Environ. Sci. Technol., 42, 3602-3608, 2008.

Clegg, S. L., Brimblecombe, P., and Wexler, A. S.: Thermodynamic model of the system $\mathrm{H}^{+}-\mathrm{NH}_{4}^{+}-\mathrm{Na}^{+}-\mathrm{SO}_{4}^{2-}-\mathrm{NO}_{3}^{-}-\mathrm{Cl}^{-}-\mathrm{H}_{2} \mathrm{O}$ at 298.15 K, J. Phys. Chem., 102(11), 2155-2171, 1998.

Duplissy, J., M. Gysel, M. R. Alfarra, J. Dommen, A. Metzger, A. S. H. Prevot, E. Weingartner, A. Laaksonen, T. Raatikainen, N. Good, S. F. Turner, G. McFiggans and U. Baltensperger: Cloud forming potential of secondary organic aerosol under near atmospheric conditions, Geophys. Res. Lett., 35(3), L03818, doi:03810.01029/02007GL031075, 2008. 
Engelhart, G. J., Asa-Awuku, A., Nenes, A., and Pandis, S. N.: $\mathrm{CCN}$ activity and droplet growth kinetics of fresh and aged monoterpene secondary organic aerosol, Atmos. Chem. Phys., 8, 3937-3949, 2008 http://www.atmos-chem-phys.net/8/3937/2008/.

Facchini, M. C., Mircea, M., Fuzzi, S., and Charlson, R. J.: Cloud albedo enhancement by surface-active organic solutes in growing droplets, Nature, 401(6750), 257-259, 1999.

Frank, H. S. and Evans, M. W.: Free Volume and Entropy in Condensed Systems .3. Entropy in Binary Liquid Mixtures - Partial Molal Entropy in Dilute Solutions - Structure and Thermodynamics in Aqueous Electrolytes, J. Chem. Phys., 13(11), 507532, 1945 .

Hegg, D. A., Gao, S., Hoppel, W., Frick, G., Caffrey, P., Leaitch, W. R., Shantz, N., Ambrusko, J., and Albrechcinski, T.: Laboratory studies of the efficiency of selected organic aerosols as CCN, Atmos. Res., 58(3), 155-166, 2001.

Huff Hartz, K. E. H., Rosenorn, T., Ferchak, S. R., Raymond, T. M., Bilde, M., Donahue, N. M., and Pandis, S. N.: Cloud condensation nuclei activation of monoterpene and sesquiterpene secondary organic aerosol, J. Geophys. Res., 110(D14), D14208, doi:14210.11029/12004JD005754, 2005.

Kalberer, M., Paulsen, D., Sax, M., Steinbacher, M., Dommen, J., Prevot, A. S. H., Fisseha, R., Weingartner, E., Frankevich, V., Zenobi, R., and Baltensperger, U.: Identification of polymers as major components of atmospheric organic aerosols, Science, 303(5664), 1659-1662, 2004.

King, S. M., T. Rosenoern, J. E. Shilling, Q. Chen and S. T. Martin: Cloud condensation nucleus activity of secondary organic aerosol particles mixed with sulfate, Geophys. Res. Lett., 34(24), L24806, doi:24810.21029/22007GL030390., 2007.

Lance, S., Medina, J., Smith, J. N., and Nenes, A.: Mapping the operation of the DMT Continuous Flow CCN counter, Aerosol Sci. Tech., 40(4), 242-254, 2006.

Ming, Y. and Russell, L. M.: Thermodynamic equilibrium of organic-electrolyte mixtures in aerosol particles, Aiche J., 48(6), 1331-1348, 2002.

Petters, M. D. and Kreidenweis, S. M.: A single parameter representation of aerosol hygroscopicity and cloud condensation nucleus activity, Atmos. Chem. Phys., 7, 1961-1971, 2007, http://www.atmos-chem-phys.net/7/1961/2007/.

Petters, M. D. and S. M. Kreidenweis: A single parameter representation of hygroscopic growth and cloud condensation nucleus activity - Part 2: Including solubility, Atmos. Chem. Phys., 8, 6273-6279, 2008, http://www.atmos-chem-phys.net/8/6273/2008/.

Petters, M. D., Prenni, A. J., Kreidenweis, S. M., and DeMott, P. J.: On measuring the critical diameter of cloud condensation nuclei using mobility selected aerosol, Aerosol Sci. Technol., 41(10), 907-913, 2007.

Pöschl, U.: Atmospheric aerosols: Composition, transformation, climate and health effects, Angewandte Chemie-International Edition, 44(46), 7520-7540, 2005.

Prausnitz, J. M., Lichtenthaler, R. N., and Azevedo, E. G.: Molecular thermodynamics of fluid-phase equilibria, Upper Saddle River, NJ, USA, Prentice Hall PTR, 1999.

Prenni, A. J., Petters, M. D., DeMott, P. J., Kreidenweis, S. M., Ziemann, P. J., Matsunaga, A., and Lim, Y. B.: Cloud drop activation of secondary organic aerosol, J. Geophys. Res., 112, D10223,
doi:10210.11029/12006JD007963, 2007.

Raymond, T. M. and Pandis, S. N.: Cloud activation of singlecomponent organic aerosol particles, J Geophys Res, 107(D24), 4787, doi:4710.1029/2002JD002159, 2002.

Rissler, J., Vestin, A., Swietlicki, E., Fisch, G., Zhou, J., Artaxo, P., and Andreae, M. O.: Size distribution and hygroscopic properties of aerosol particles from dry-season biomass burning in Amazonia, Atmos. Chem. Phys., 6, 471-491, 2006, http://www.atmos-chem-phys.net/6/471/2006/.

Roberts, G. C. and Nenes, A.: A continuous-flow streamwise thermal-gradient $\mathrm{CCN}$ chamber for atmospheric measurements, Aerosol Sci Tech, 39(3), 206-221, 2005.

Rose, D., Gunthe, S. S., Mikhailov, E., Frank, G. P., Dusek, U., Andrea, M. O., and Pöschl, U.: Calibration and measurement uncertainties of a continuous-flow cloud condensation nuclei counter (DMT-CCNC): CCN activation of ammonium sulfate and sodium chloride aerosol particles in theory and experiment, Atmos. Chem. Phys., 8, 1153-1179, 2008, http://www.atmos-chem-phys.net/8/1153/2008/.

Saathoff, H., Naumann, K. H., Schnaiter, M., Schock, W., Mohler, O., Schurath, U., Weingartner, E., Gysel, M., and Baltensperger, U.: Coating of soot and $\left(\mathrm{NH}_{4}\right)(2) \mathrm{SO}_{4}$ particles by ozonolysis products of alpha-pinene, J. Aerosol. Sci., 34(10), 1297-1321, 2003.

Stratmann, F., Kiselev, A., Wurzler, S., Wendisch, M., Heintzenberg, J., Charlson, R. J., Diehl, K., Wex, H., and Schmidt, S. Laboratory studies and numerical simulations of cloud droplet formation under realistic supersaturation conditions, J. Atmos. Ocean. Technol., 21(6), 876-887, 2004.

Svenningsson, B., H. C. Hansson, A. Wiedensohler, K. Noone, J. Ogren, A. Hallberg and R. Colvile: Hygroscopic Growth of Aerosol-Particles and Its Influence on Nucleation Scavenging inCloud - Experimental Results from Kleiner-Feldberg, J. Atmos. Chem., 19(1-2), 129-152, 1994.

Topping, D. O., McFiggans. G. B.. and Coe. H.: A curved multicomponent aerosol hygroscopicity model framework: Part 2 Including organic compounds, Atmos. Chem. Phys., 5, 12231242,2005 , http://www.atmos-chem-phys.net/5/1223/2005/.

Tuckermann, R. and Cammenga, H. K.: The surface tension of aqueous solutions of some atmospheric water-soluble organic compounds, Atmos. Environ., 38(36), 6135-6138, 2004.

VanReken, T. M., Ng, N. L., Flagan, R. C., and Seinfeld, J. H.: Cloud condensation nucleus activation properties of biogenic secondary organic aerosol, J. Geophy. Res., 110(D7), D07206, doi:07210.01029/02004JD005465, 2005.

Varutbangkul, V., Brechtel, F. J., Bahreini, R., Ng, N. L., Keywood, M. D., Kroll, J. H., Flagan, R. C., Seinfeld, J. H., Lee, J. H., and Goldstein, A. H.: Hygroscopicity of secondary organic aerosols formed by oxidation of cycloalkenes, monoterpenes, sesquiterpenes, and related compounds, Atmos. Chem. Phys., 6, 23672388, 2006, http://www.atmos-chem-phys.net/6/2367/2006/.

Virkkula, A., Van Dingenen, R., Raes, F., and Hjorth, J.: Hygroscopic properties of aerosol formed by oxidation of limonene, alpha-pinene, and beta-pinene, J. Geophys. Res., 104(D3), 35693579, 1999.

Wex, H., Hennig, T., Salma, I., Ocskay, R., Kiselev, A., Henning, S., Massling, A., Wiedensohler, A., and Stratmann, F.: 
Hygroscopic growth and measured and modeled critical supersaturations of an atmospheric HULIS sample, Geophys Res Lett, 34(2), L02818, doi:02810.01029/02006GL028260, 2007.

Wex, H., F. Stratmann, D. Topping and G. McFiggans: The Kelvin versus the Raoult term in the Köhler equation, J. Atmos. Sci., 65, 4004-4016, doi:4010.1175/2008JAS2720.4001, 2008 b.

Wex, H., Petters, M. D., Carrico, C. M., Hallbauer, E., Massling, A., McMeeking, G. R., Poulain, L., Wu, Z., Kreidenweis, S. M., and Stratmann, F.: Towards Closing the Gap between Hygroscopic Growth and Activation for Secondary Organic Aerosol: Part I - Evidence from Measurements, Atmos. Chem. Phys. Discuss., 9, 3987-3997, 2009, http://www.atmos-chemphys.net/9/3987/2009/acp-9-3987-2009.html.
Ziese, M., Wex, H., Nilsson, E. D., Salma, I., Ocskay, R., Hennig, T., Massling, A., and Stratmann, F.: Hygroscopic growth and activation of HULIS particles: experimental data and a new iterative parameterization scheme for complex aerosol particles, Atmos. Chem. Phys., 8, 1855-1866, 2008,

http://www.atmos-chem-phys.net/8/1855/2008/. 